\title{
Communication
}

\section{Food-Grade Biorefinery Processing of Macroalgae at Scale: Considerations, Observations and Recommendations}

\author{
Jessica M. M. Adams ${ }^{1, * \mathbb{D}}$, S. Michael Morris ${ }^{1}$, Laura Steege ${ }^{1}$, Joanne Robinson ${ }^{2}$ and Charles Bavington ${ }^{2}$ \\ 1 Institute of Biological, Environmental and Rural Sciences (IBERS), Aberystwyth University, Gogerddan, \\ Aberystwyth SY23 3EE, UK; tem@aber.ac.uk (S.M.M.); lsteege@hotmail.co.uk (L.S.) \\ 2 Oceanium Ltd., Malin House, European Marine Science Park, Oban PA37 1SZ, UK; \\ joanne@oceanium.co.uk (J.R.); charlie@oceanium.co.uk (C.B.) \\ * Correspondence: jaa@aber.ac.uk; Tel.: +44-(0)1970-823152
}

check for updates

Citation: Adams, J.M.M.; Morris, S.M.; Steege, L.; Robinson, J.; Bavington, C. Food-Grade Biorefinery Processing of Macroalgae at Scale: Considerations, Observations and Recommendations. J. Mar. Sci. Eng. 2021, 9, 1082. https://doi.org/ $10.3390 /$ jmse9101082

Academic Editors: Laurie Hofmann and Stefan Sebök

Received: 31 August 2021

Accepted: 30 September 2021

Published: 2 October 2021

Publisher's Note: MDPI stays neutral with regard to jurisdictional claims in published maps and institutional affiliations.

Copyright: (c) 2021 by the authors. Licensee MDPI, Basel, Switzerland. This article is an open access article distributed under the terms and conditions of the Creative Commons Attribution (CC BY) license (https:/ / creativecommons.org/licenses/by/ $4.0 /)$.

\begin{abstract}
Using brown seaweed kelp species Saccharina latissima and Laminaria digitata as feedstocks, a set of pilot-scale macroalgae processing batches were conducted (50-200 kg per batch) for the production of a range of food-grade liquid and solid fractions. The aim of this communication is to relay a number of lessons learnt during this period in combination with previous relevant observations and considerations for others who are intending to process macroalgae at scale. The novelty of this paper is thus to form a bridge between academic findings and practical knowhow. Considerations covers material diversity; abiotic and biotic impact and variation; and supply chain considerations. Observations covers milling and cutting; equipment requirements; and acids including their effects on heavy metals, especially lead. Recommendations summarises key points from this pilot-scale and previous work. These include: harvest seasonality, water quality and proximity to processing facilities; minimising contaminants within the macroalgae such as stones and shells; considering equipment composition and volume for all steps and processes including final product quality; acid choice and its effects on both the equipment used and the metals bioaccumulated within the macroalgae.
\end{abstract}

Keywords: bioactives; contaminants; cutting; HACCP; heavy metals; mineral acid; pilot-scale; press; seaweed; stainless steel

\section{Introduction}

As global populations grow, the demands for land increase. The logical step is to move a greater proportion of production into the water and to diversify foods grown there. Macroalgae (seaweeds) do not require land, fresh water or fertilisers to grow [1] and are naturally rich in minerals, vitamins and polyunsaturated fatty acids [2]. The global market for macroalgae products is increasing annually, with a compound annual growth rate (CAGR) of 5.8\% forecast between 2019 and 2027 based primarily on increases of seaweed in food products [3]. Macroalgae demand is being met by supply through cultivation, with nearly twice as much between 2009 (18.7 mt/ USD 7.8 bill) and 2018 (32.4 mt/ USD 13.3 bill) produced this way, making $97.1 \%$ macroalgae sold now harvested from cultivated material [4]. Approximately 85\% of seaweeds are used either directly or indirectly as food products for human consumption [5], making this the predominant market for macroalgae. This market opportunity has been identified by numerous small and medium enterprises globally, with many lacking previous experience working with macroalgae.

Between September 2020 and January 2021, $1000 \mathrm{~kg}$ wet weight brown macroalgae kelps (Saccharina latissima (Linnaeus) and Laminaria digitata (Hudson)) were processed in eight sequential batches. Staff from IBERS, Aberystwyth University project managed and operated pilot-scale ERDF-project BEACON equipment based in a food-grade facility on site. A number of insights considered of value to others intending to process macroalgae in food-grade conditions at scale were learnt during this period and have been combined with previous processing points and macroalgal knowledge of value from academic studies and 
industrial, unpublished studies. These findings are detailed within three subsequent sections termed Pre-Processing Considerations, Observations and Recommendations below.

\section{Methodology}

\subsection{Resource and Pre-Process Milling}

Macroalgae was sourced from three origins for this contract research, with the UK material wild-harvested and the French material from cultivated stock. Weights given below are for milled material used in the processing batches (2.2).

Laminaria digitata $(200 \mathrm{~kg})$ was harvested from Cornwall, UK in the week commencing 8 June 2020, frozen on collection, and transported to Aberystwyth under frozen conditions before storing at $-20{ }^{\circ} \mathrm{C}$. Saccharina latissima $1(400 \mathrm{~kg}$ ) was harvested in Oban, UK on 23 August 2020 and transported in boxes under ice to Aberystwyth on the 24 August 2020. Saccharina latissima 2 was supplied as dried, pre-milled material in $2 \times 25 \mathrm{~kg}$ sacks (rehydrated weight $400 \mathrm{~kg}$ ) from Algolesko (Loctudy, France).

L. digitata material was removed from $-20{ }^{\circ} \mathrm{C}$ on 23 August with bags of approx. $20 \mathrm{~kg}$ spread on trays and allowed to defrost to room temperature overnight. S. latissima 1 and L. digitata were milled on 24 August 2020 using a FAM Yuran mill (FAM Stumabo, Birmingham, UK) set to $4 \mathrm{~mm}^{2}$ mill size. L. digitata was passed through the mill twice to reduce particle size after insufficient reduction in size from the first mill. Once milled, material was transferred to lidded storage boxes holding an average $12.7 \mathrm{~kg}$ (S. latissima 1) and $15.2 \mathrm{~kg}$ (L. digitata) per box. Boxes were stored at $-20^{\circ} \mathrm{C}$ before defrosting at room temperature prior to processing.

\subsection{Batch Processing}

Batches began with smaller weights and increased through the contract. Batches 1 and 2 were 51 and $49 \mathrm{~kg}$ of $S$. latissima 1 and L. digitata, respectively. Batches $3-5$ were $S$. latissima 1 at 78, 131 and $154 \mathrm{~kg}$, respectively. Batch 6 was L. digitata at $162 \mathrm{~kg}$; batches 7 and 8 were S. latissima 2 at $25 \mathrm{~kg}$ dry weight (approximately $200 \mathrm{~kg}$ wet equivalent) each.

Each batch consisted of two water washes with decanter centrifuge separation between and after washes; two dilute sulphuric acid washes with decanter centrifugation as before; particle treatment through maceration (Gamme master MX-DMX-410, Dymanic, Mortagne sur Sevre, France) or cavitation (company prototype, specifics confidential); an enzyme hydrolysis incubation, enzyme denature step and separation through decanter centrifugation; neutralisation of the solid fraction and drying of the solid fraction. An outline processing diagram is shown in Figure 1. Due to the commercially sensitive nature of this work, further specifics cannot be reported on within this paper.

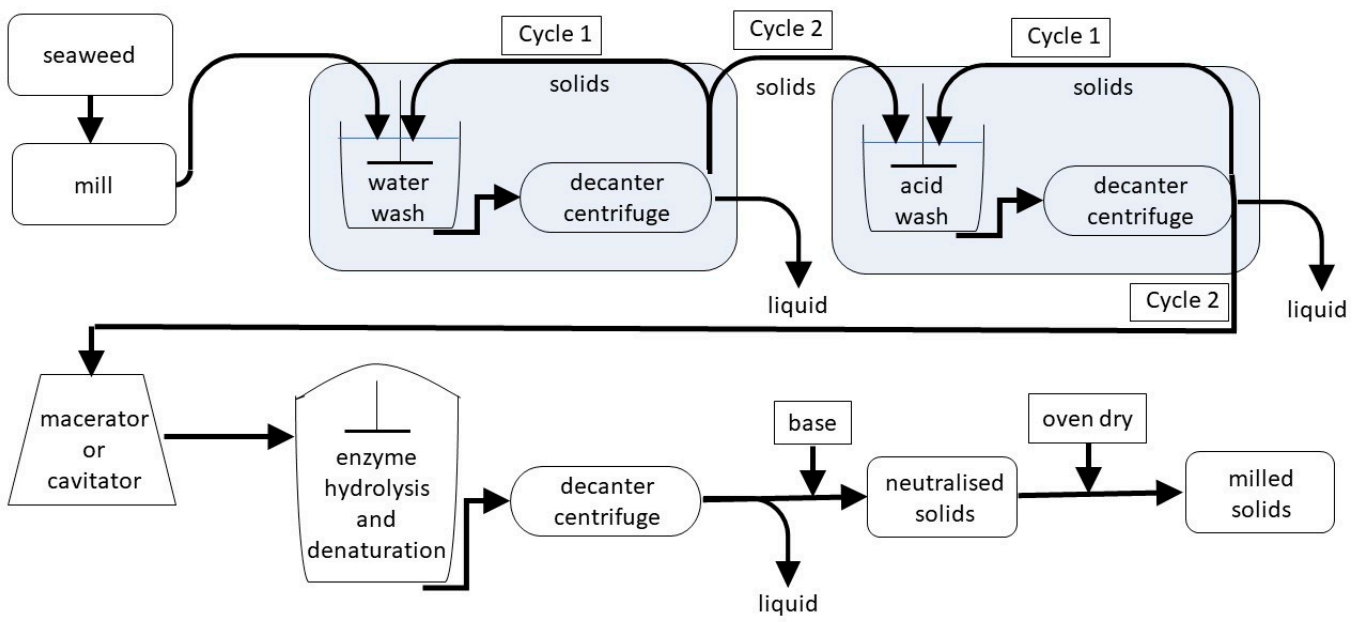

Figure 1. Schematic of macroalgae processing at scale, showing the main steps of the process. Inverted ' $\mathrm{T}^{\prime}$ 's indicate stirring. Between steps, material was stored at $4{ }^{\circ} \mathrm{C}$ (overnight) or at $-20{ }^{\circ} \mathrm{C}$ (longer term). 


\section{Pre-Processing Considerations}

\subsection{Resource Diversity}

Macroalgae, or seaweeds, are very generalised terms for organisms which predominantly grow in the marine environment and share some characteristics to one another but which are highly evolutionarily diverse. Frequently divided into colours of red, green and brown within the divisions Rhodophyta, Chlorophyta and the class Phaeophyceae, respectively [6], each algal 'type' has different structural and storage compounds to the others. Thus, 'seaweed processing' will differ considerably both between and within these divisions. Macroalgae within Rhodophyta contain the hydrocolloid agar (processed from, e.g., Gracilaria and Gelidium genera) or carrageenan (processed from, e.g., Kappaphycus and Eucheuma genera); Phaeophyceae contain the hydrocolloid alginate (processed from, e.g., Laminaria and Macrocystis genera) [7]. Chlorophyta, e.g., Ulva spp. do not contain hydrocolloids but do contain ulvan, a sulphated polysaccharide with low viscosity properties [8]. These hydrocolloids all have identified bioactive properties, such as boosting the immune system and demonstrated anti-cancer properties [9]. Other commercially important compounds with similar or enhanced bioactivities are also 'type' specific, with Phaeophyceae containing fucoidan, laminarin and phycarine; and Rhodophyta containing porphyran $[9,10]$. All seaweeds also contain high concentrations of elements, typically detected through ash quantification [2], and with these different structural and storage molecules can and often do react or handle differently to terrestrial biomass. This is something which is regularly overlooked and can cause significant issues unless initially considered.

\subsection{Variation of Feedstock-Abiotic}

As with terrestrial crops, the chemical composition of macroalgae varies greatly based on the stage of cultivation and the environment in which it is grown. For example, in L. digitata, the desirable storage carbohydrate laminarin is minimally abundant early in spring but peaks later in the summer as the algae matures. The relative abundance of elements, such as alkali metals, in the algal tissues is inversely related to laminarin content, indicating tradeoffs in physiological requirements throughout the year [11,12]. Alternatively, the presence of some compounds, such as alginic acid, is constant throughout the year [13]. Location is also highly impactful, with macroalgae typically growing better in areas containing high concentrations of dissolved nutrients, low resuspended organic material and sufficient light penetration, such as that seen in deeper coastal waters [14]. Macroalgae are bioaccumulators, meaning they will take up metals, including heavy metals, to concentrations above the surrounding environment and potentially exceeding food safety limits [15]. Harvesting should therefore occur from areas with low heavy metal content, with metal concentrations determined in the macroalgae and their removal considered if required in downstream processing.

Other additional factors include water temperature, light irradiance and salinity concentrations [16]. If the macroalgae are cultivated, set growth depth [17] can be controlled, as can seedling age and density, leading to a more standardised, higher quality 'crop' than from wild harvesting with potentially few opportunistic other algae present. Hatchery conditions can also affect off-shore macroalgae composition; for example, in off-shore cultivated $U$. fenestrata, low seedling density increased the proportion of carbohydrate in the harvested material, but high seedling density was the most important factor for producing high total biomass [18].

\subsection{Variation of Feedstock—Biotic}

Biotic factors, such as sea snails and other herbivores grazing over the algae, cause algal tissue wounding. This can create cracks in the underlying tissues leading to mechanical damage such as a reduction in stiffness, strength or extensibility, in turn leading to an increased propensity in breaking and subsequent biomass loss [19]. Differently sourced seaweeds may also generate different responses to biotic and abiotic stresses; for example, 
the Phaeophyceae Silvetia compressa from northern California responded to low levels of herbivore grazing whereas $S$. compressa from southern California did not, even after 24 days of acclimatization [20]. Epiphyte presence and abundance is another consideration, both for the health and yield of the cultivated seaweed which could be negatively affected [21]; and for contamination in subsequent processing.

\subsection{Supply Chain}

Large scale farmed macroalgae biorefinery processing is dependent not only on the availability of macroalgae feedstock but also that the supplied macroalgae is of the correct quality and price. Proximity of farmed material to processing location is also a strong consideration, as harvested macroalgae is subject to rapid microbial degradation [22] and composition losses, e.g., carbohydrate and polyphenol losses in kelps [23]. If no steps are taken to stabilise fresh macroalgae, microbiological counts of spoilage bacteria (aerobic colony count) very rapidly exceed the upper limit of determination, and yeasts and moulds start to be problematic [24]. Unpublished industry-led studies [25] have shown that microbial degradation is critically dependent on both seawater temperature and storage temperature after harvest. Sea temperatures for Scotland are $6-9{ }^{\circ} \mathrm{C}$ in winter, $12-15{ }^{\circ} \mathrm{C}$ in summer; elsewhere round the UK, typical minima could be as low as $4{ }^{\circ} \mathrm{C}$ but in summer typical maxima could be up to $19^{\circ} \mathrm{C}$. These variations are strongly dependent on depth and weather [26] as well as tidal mixing [27] and with regional and local variation occurring outside these ranges. Unpublished industry-led studies [25] have determined a number of options to manage stability during and after harvest.

\subsubsection{Initial Processing}

1. Temperature control during harvest. Macroalgae can be held floating in the sea in nets using the water as a coolant and isotonic storage facilities to delay deterioration for extended periods. For example, deterioration of algae was only detected after two weeks in French L. hyperborea fragments [28].

2. Temperature control on land. Keeping the macroalgae cool prior to processing is critical to reduce or prevent spoilage; simple steps such as using insulated bulk containers, packing nets of macroalgae with ice, or keeping out of strong sunlight all help reduce heating.

3. Stabilisation prior to processing. There are a range of stabilisation options which will depend on downstream processes and end products. For short-term stabilisation: fresh macroalgae should be held between $1-8{ }^{\circ} \mathrm{C}$ before processing. If chopping macroalgae, storing the pieces in insulated tanks slows degradation as does anaerobic storage. For medium-term stabilisation, blast freezing is recommended. For long term storage, drying to $<10 \%$ moisture is recommended.

4. Stabilisation during processing. Use Hazard Analysis and Critical Control Points (HACCP) analysis or other national food standard guidance [29] to identify critical control points to control microbial load during processing, including possible kill steps.

\subsubsection{Final Product}

Almost all macroalgae biorefinery processing will include the manufacture of food products, with European uses focussed mainly on the production of hydrocolloid thickeners [2]. The processor must control all of the food safety hazards that are associated with macroalgae, from concentrations of iodine and heavy metals [15] to those from the macroalgae environment, including foreign bodies, pathogenic microbes, allergens including crustaceans, and environmental contaminants such as polyaromatic hydrocarbons [30]. These hazards should be managed by standard food safety prerequisites (e.g., hygiene controls and pest control), and through a comprehensive food standard plan such as HACCP. This plan needs to be built into the whole supply chain, i.e., the farmer should also implement a plan for their role in the macroalgae production. The processor and farmer 
should work together to establish a traceability system which ensures 100\% traceability of all macroalgae from harvest through to finished products. Biorefinery processing critical control points will depend on the processes being used, but are likely to include 'kill' steps to eliminate pathogenic bacteria, and steps to reduce heavy metals and iodine. Processing must be supported by a programme of monitoring to ensure product compliance with regulations and in-house specification, enabling the product to be sold [25].

\section{Observations}

\subsection{Milling and Cutting}

Previous experience has shown that different seaweed types mill and handle differently. Brown macroalgae contain the hydrocolloid alginate, which not only acts as a thickeners and gelling agent once extracted [7] but also when processing. This also means that putting brown seaweeds such as the kelp L. digitata through a screw press yields almost no liquid [1] unless other additives such as dilute hydrochloric acid are included [31] despite their high moisture content. In contrast, screw pressing the red seaweed Palmaria palmata gives a good juice yield [32], as does screwpressing green Ulva spp. [33]. This does offer opportunities for brown macroalgae processing to either use juicing systems such as a screw press for particle size reduction, or to use cutting machines without concern regarding significant moisture or bioactive loss.

In our scaled processing, one key observation was that when using commercial cutting machines, it is imperative that the macroalgae material is clean, taken either from rope cultivation or hand-harvested with the holdfasts left at sea. Even a few kelps taken from the surrounding environment with foreign bodies within their haptera, such as stones or toughened shells, e.g., top shells (Steromphala spp.), cause damage such as dents and nicks to arise on cutting blades, causing incomplete cutting to subsequent samples.

\subsection{Equipment Considerations}

In previous lab-based studies, glassware has been typically used with autoclaving as the sterilising route of choice. As processing scale expands, glassware and autoclaving will become unviable, with vessels typically replaced by plasticware, especially if disposable; or metal containers, potentially with liners; with cleaning conducted in situ using steam or disinfection regimes. Equipment has to comfortably take all batch volumes for all relevant steps to be held within it.

For food-grade processing, a typical clean-in-place regime consists of a pre-rinse, caustic wash, water rinse, acid wash, water rinse, and then sterilisation in place. Sterilisation can be by chemical disinfectant or steam. Chemical disinfectants should be effective, safe and easy to use, easy to rinse away, and should leave no toxic residues on surfaces [34]. Steam sterilisation is a reliable method of sterilisation; however, with it comes a high energy demand and high capital cost, as equipment must be designed to withstand the required steam pressure [35].

Glass vessels for small-scale work have a range of advantages, including being corrosion-resistant, non-toxic and transparent, allowing easy inspection of its contents [36]. However, at a large scale, glass vessels are unsuitable for in-situ steam sterilisation as any damage or cracks in the glass could result in breakage; ideally if a vessel is too large to fit in an autoclave, it should not be made of glass, although chemical disinfection can be used [35]. At a larger scale, disposable plastic process bags for liquid storage and single-use bioreactors with disposable bags have the advantage of no cleaning or sterilisation requirements, which, along with quick and easy deployment, shortens overall processing time. However, disadvantages include limited options for mixing contents and size limitation, with most single bioreactors built up to $2000 \mathrm{~L}$ and the largest size of single use bioreactors currently available at only $6000 \mathrm{~L}$ [37]. Stainless steel vessels are widely used in bioprocessing, making them well established and understood; advantages over single-use plastic reactors include larger capacities and better mixing, heat transfer and oxygen transfer [36]. 
Disadvantages include higher maintenance requirements and for cleaning and sterilisation in place to be built in, resulting in high utility costs and longer processing times.

In our scaled processing, we had to calculate all the weights and volumes needed to complete all steps of the process, then review, as these occasionally resulted in unanticipated bottlenecks. For smaller batches $(<100 \mathrm{~kg}$ macroalgae), initial washes were conducted in $250 \mathrm{~L}$ stainless steel vessels with integrated scales, allowing highly accurate liquid addition as a proportion of macroalgae present. For batches $>100 \mathrm{~kg}$ wet weight, water and acid washes were conducted in a high-density polyethylene intermediate bulk container (IBC). For both vessel and IBC, a stainless steel overhead stirrer was used to provide mixing of the slurries. For subsequent processing steps, containers and/or mixing devices were composed of stainless steel or non-degrading purpose-made plastics.

Sample quality was principally maintained through a short processing schedule and storage at $4{ }^{\circ} \mathrm{C}$ overnight between steps. Due to the acidic nature of the material for much of the processing and a high-temperature enzyme denaturing step, microbial degradation was not a major concern. Equipment cleaning was primarily conducted using pressurised hot water and physical cleaning; again, due to the low $\mathrm{pH}$ of the macroalgae, a partial clean-in-place treatment was occurring during processing. For non-accessible regions such as tubing and pipework, additional cleaning regimes were applied involving circulation of hot detergent solutions. Equipment was also reserved for this feedstock only during the processing of these batches to prevent contamination from other sources.

\subsection{Acids}

In addition to cleaning and practical issues, the material that equipment is constructed from has further impacts regarding the chemicals used. The initial step (and typical first step) in macroalgae processing is that of fresh water washes. These are conducted to remove contaminating particulates but concurrently extract soluble components such as laminarin and minerals [38]. Subsequent washes with acidic solutions further solubilise compounds and metals [39], necessary for reducing any potential heavy metal concentrations in the macroalgae product. The primary objective of acidic washes for Phaeophyceae, though, is to convert insoluble calcium alginate (with trace quantities of strontium alginate and magnesium alginate also present $[40,41]$ ) to alginic acid. This is an intermediate step in the conversion to soluble sodium alginate [7]. In order to achieve the primary ion exchange reaction where alginate's divalent metal counterions are replaced with hydrogen ions, it is important that a strong acid is used, and that the concentrations used are sufficient to maximise the displacement of the divalent elements [7]. Hydrochloric acid and sulphuric acids are both suitable strong acids for converting divalent cation salts of alginate to alginic acid.

However, these acids differ in their effect on larger-scale metal equipment. Hydrochloric acid is a reducing acid without the oxidising properties required by stainless steels to maintain their surface layer, meaning that common stainless steels are considered non-resistant to hydrochloric acid at any temperature or concentration, and higher grade stainless steels provide only a limited resistance against it [42]. Sulphuric acid is more complex, with most stainless steel types resistant to corrosion at low or high concentrations but becoming damaged at intermediate concentrations. This can occur inadvertently, as sulphuric acid has a high affinity for water. This means that a safely concentrated acid can become diluted enough to display corrosive properties following water absorption from the surrounding environment [43], and rigorous controls and monitoring will need to be adhered to.

A further issue regarding sulphuric acid is that unpublished, industry-led research [25], confirmed through these scaled-up batches, has identified an increase in the relative concentration of lead $(\mathrm{Pb})$ in the remaining solid. In previous small-scale and in these pilot-scale trials it was shown to raise the lead concentration above $0.5 \mathrm{ppm}$, which is at or above the regulatory limit for the majority of listed foodstuffs [44]. Lead cations have been shown to have a higher affinity to brown algal biomass than other heavy metals such as 
cadmium and nickel, causing precipitation on the cell wall matrix [45]. It appears that this occurs because lead sulphate $\left(\mathrm{PbSO}_{4}\right)$ is almost insoluble in water [46] and it is therefore 'trapped' in the solid and not extracted. In contrast, hydrochloric acid-derived lead chloride $\left(\mathrm{PbCl}_{2}\right)$ is more soluble, with the solubility increasing if high-concentration chloride is used as higher-order chlorocomplexes are formed [47]; collectively, this means that lead is removed during hydrochloric acid washes. Previous small-scale and these pilot-scale studies on kelp did not see an increase in other heavy metals tested (including cadmium $(\mathrm{Cd})$, mercury $(\mathrm{Hg})$ and inorganic arsenic (iAs)) indicating this is an issue predominantly affecting lead over other elements [25].

\title{
5. Recommendations
}

Processing at pilot scale has highlighted a number of issues not foreseen in lab-scale processing. For those considering scaling up processing, below are several recommendations for consideration which have either arisen during recent pilot-scale processing or are from previous experiences but considered of value.

\subsection{Macroalgae Feedstock}

- Optimise the condition of material, harvesting proximity and time of year harvested for the main extraction product of interest.

- Minimise level of contamination to acceptable levels, both for snails and stones and for epiphytes.

\subsection{Equipment}

- Consider the robustness and specifics of all equipment to be used, including vessels, centrifuges and pumps, to identify potential weak points or bottlenecks.

- $\quad$ Review alternatives, e.g., using plastic and non-metal presses, retrofitting existing equipment if needed. Review whether this will affect cleaning or processing regimes.

- Review working volumes for processing, including for future scale-up. One large vessel is often preferable to replicating steps using a smaller vessel.

\subsection{Acid}

- Consider the impact of selected acid on both the equipment used (especially if constructed of stainless steel or other metals) and the metals within the macroalgae, taking into account the final product use.

\begin{abstract}
Author Contributions: Conceptualization, J.M.M.A., S.M.M. and C.B.; seaweed batch processing coordination and qualitative assessments J.M.M.A., J.R. and C.B.; writing-original draft preparation, J.M.M.A., C.B. and L.S.; writing-review and editing, J.M.M.A., C.B., S.M.M., L.S. and J.R.; project administration, J.R. and J.M.M.A.; funding acquisition, C.B. All authors have read and agreed to the published version of the manuscript.
\end{abstract}

Funding: This research was funded by SMART grant IUK 106087 using pilot-scale equipment and expertise provided by project BEACON+, ERDF grant number 80851.

Institutional Review Board Statement: Not applicable.

Informed Consent Statement: Not applicable.

Data Availability Statement: Not available due to the commercial aspects of this work.

Acknowledgments: Support given by BEACON technical team.

Conflicts of Interest: The authors declare no conflict of interest.

\section{References}

1. Adams, J.M.M.; Bleathman, G.; Thomas, D.; Gallagher, J.A. The effect of mechanical pre-processing and different drying methodologies on bioethanol production using the brown macroalga Laminaria digitata (Hudson) JV Lamouroux. Environ. Boil. Fishes 2017, 29, 2463-2469. [CrossRef] 
2. Biancarosa, I.; Belghit, I.; Bruckner, C.G.; Liland, N.S.; Waagbo, R.; Amlund, H.; Heesch, S.; Lock, E.-J. Chemical characterization of 21 species of marine macroalgae common in Norwegian waters: Benefits of and limitations to their potential use in food and feed. J. Sci. Food Agric. 2018, 98, 2035-2042. [CrossRef] [PubMed]

3. Fortune Business Insights. In Commercial Seaweed Market Size, Share and COVID-19 Impact Analysis, by Type (Red Seaweed, Brown Seaweed, and Green Seaweed), form (Flakes, Powder, and Liquid), End-Uses (Food E Beverages, Agricultural Fertilizers, Animal Feed Additives, Pharmaceuticals, and Cosmetics E Personal Care), and Regional Forecast, 2020-2027; Grand View Research: San Francisco, CA, USA, 2021. Available online: https://www.fortunebusinessinsights.com/industry-reports/commercial-seaweed-market-100077 (accessed on 21 June 2021).

4. FAO. Yearbook. Fishery and Aquaculture Statistics 2018; FAO: Rome, Italy, 2020. [CrossRef]

5. FAO. The Global Status of Seaweed Production, Trade and Utilization; FAO: Rome, Italy, 2018; p. 120.

6. Sze, P. A Biology of the Algae, 3rd ed.; WCB McGraw-Hill: New York, NY, USA, 1998.

7. McHugh, D. A Guide to the Seaweed Industry; Fisheries technical paper 441; Food and Agriculture Organisation of the United Nations (FAO): Rome, Italy, 2003; p. 105.

8. Robic, A.; Sassi, J.-F.; Dion, P.; Lerat, Y.; Lahaye, M. Seasonal variability of physicochemical and rheological properties of ulvan in two Ulva species (Chlorophyta) from the brittany coast1. J. Phycol. 2009, 45, 962-973. [CrossRef]

9. Holdt, S.L.; Kraan, S. Bioactive compounds in seaweed: Functional food applications and legislation. J. Appl. Phycol. 2011, 23, 543-597. [CrossRef]

10. Fletcher, H.; Biller, P.; Ross, A.; Adams, J. The seasonal variation of fucoidan within three species of brown macroalgae. Algal Res.-Biomass Biofuels Bioprod. 2017, 22, 79-86. [CrossRef]

11. Adams, J.M.M.; Ross, A.B.; Anastasakis, K.; Hodgson, E.M.; Gallagher, J.A.; Jones, J.M.; Donnison, I.S. Seasonal variation in the chemical composition of the bioenergy feedstock Laminaria digitata for thermochemical conversion. Bioresour. Technol. 2011, 102, 226-234. [CrossRef]

12. Adams, J.M.M.; Toop, T.A.; Donnison, I.S.; Gallagher, J.A. Seasonal variation in Laminaria digitata and its impact on biochemical conversion routes to biofuels. Bioresour. Technol. 2011, 102, 9976-9984. [CrossRef] [PubMed]

13. Black, W.A.P. The seasonal variation in weight and chemical composition of the common British Laminariaceae. J. Mar. Biol. Assoc. United Kingd. 1950, 29, 45-72. [CrossRef]

14. Bartsch, I.; Wiencke, C.; Bischof, K.; Buchholz, C.; Buck, B.H.; Eggert, A.; Feuerpfeil, P.; Hanelt, D.; Jacobsen, S.; Karez, R.; et al. The genus Laminaria sensu lato: Recent insights and developments. Eur. J. Phycol. 2008, 43, 1-86. [CrossRef]

15. Monteiro, M.S.; Sloth, J.; Holdt, S.L.; Hansen, M. Analysis and Risk Assessment of Seaweed; National Food Insititue, Technical University of Denmark: Lyngby-Taarbæk, Denmark, 2019; p. 11. [CrossRef]

16. Visch, W.; Bergström, P.; Nylund, G.M.; Peterson, M.; Pavia, H.; Lindegarth, M. Spatial differences in growth rate and nutrient mitigation of two co-cultivated, extractive species: The blue mussel (Mytilus edulis) and the kelp (Saccharina latissima). Estuar. Coast. Shelf Sci. 2020, 246, 107019. [CrossRef]

17. Sharma, S.; Neves, L.; Funderud, J.; Mydland, L.T.; Øverland, M.; Horn, S.J. Seasonal and depth variations in the chemical composition of cultivated Saccharina latissima. Algal Res.-Biomass Biofuels Bioprod. 2018, 32, 107-112. [CrossRef]

18. Steinhagen, S.; Enge, S.; Larsson, K.; Olsson, J.; Nylund, G.; Albers, E.; Pavia, H.; Undeland, I.; Toth, G. Sustainable Large-Scale Aquaculture of the Northern Hemisphere Sea Lettuce, Ulva fenestrata, in an Off-Shore Seafarm. J. Mar. Sci. Eng. 2021, 9, 615. [CrossRef]

19. Burnett, N.P.; Koehl, M.A.R. Mechanical properties of the wave-swept kelp, Egregia menziesii, change with season, growth rate, and herbivore wounds. J. Exp. Biol. 2019, 222, jeb.190595. [CrossRef] [PubMed]

20. Jones, E.; Long, J.D. Geographic variation in the sensitivity of an herbivore-induced seaweed defense. Ecology 2018, 99, 1748-1758. [CrossRef]

21. Haugland, B.T.; Armitage, C.S.; Kutti, T.; Husa, V.; Skogen, M.D.; Bekkby, T.; Carvajalino-Fernandez, M.A.; Bannister, R.J.; White, C.A.; Norderhaug, K.M.; et al. Large-scale salmon farming in Norway impacts the epiphytic community of Laminaria hyperborea. Aquac. Environ. Interact. 2021, 13, 81-100. [CrossRef]

22. Rieper-Kirchner, M. Macroalgal decomposition: Laboratory studies with particular regard to microorganisms and meiofauna. Helgol. Meeresunters. 1990, 44, 397-410. [CrossRef]

23. Stévant, P.; Marfaing, H.; Rustad, T.; Sandbakken, I.; Fleurence, J.; Chapman, A. Nutritional value of the kelps Alaria esculenta and Saccharina latissima and effects of short-term storage on biomass quality. J. Appl. Phycol. 2017, 29, 2417-2426. [CrossRef]

24. Sánchez-García, F.; Hernández, I.; Palacios, V.; Roldán, A. Freshness Quality and Shelf Life Evaluation of the Seaweed Ulva rigida through Physical, Chemical, Microbiological, and Sensory Methods. Foods 2021, 10, 181. [CrossRef]

25. Bavington, C. Industry-led studies. 2021; Unpublished personal communication.

26. Morris, D.J.; Pinnegar, J.; Maxwell, D.L.; Dye, S.R.; Fernand, L.J.; Flatman, S.; Williams, O.J.; Rogers, S.I. Over 10 million seawater temperature records for the United Kingdom Continental Shelf between 1880 and 2014 from 17 Cefas (United Kingdom government) marine data systems. Earth Syst. Sci. Data 2018, 10, 27-51. [CrossRef]

27. Arnold, A.K.; Lewis, H.W.; Hyder, P.; Siddorn, J.; O’Dea, E. The Sensitivity of British Weather to Ocean Tides. Geophys. Res. Lett. 2021, 48, e2020GL090732. [CrossRef] 
28. De Bettignies, F.; Dauby, P.; Thomas, F.; Gobet, A.; Delage, L.; Bohner, O.; Loisel, S.; Davoult, D. Degradation dynamics and processes associated with the accumulation of Laminaria hyperborea (Phaeophyceae) kelp fragments: An in situ experimental approach. J. Phycol. 2020, 56, 1481-1492. [CrossRef]

29. FSA. Hazard Analysis and Critical Control Point (HACCP). 2017. Available online: https://www.food.gov.uk/businessguidance/hazard-analysis-and-critical-control-point-haccp (accessed on 21 June 2021).

30. Banach, J.L.; Hoek-van den Hil, E.F.; Van Der Fels-Klerx, H.J. Food safety hazards in the European seaweed chain. Compr. Rev. Food Sci. Food Saf. 2020, 19, 332-364. [CrossRef]

31. Gallagher, J.A.; Turner, L.B.; Adams, J.M.M.; Dyer, P.W.; Theodorou, M.K. Dewatering treatments to increase dry matter content of the brown seaweed, kelp (Laminaria digitata ((Hudson) JV Lamouroux)). Bioresour. Technol. 2017, 224, 662-669. [CrossRef]

32. Gallagher, J.A.; Turner, L.B.; Adams, J.M.M.; Barrento, S.; Dyer, P.W.; Theodorou, M.K. Species variation in the effects of dewatering treatment on macroalgae. J. Appl. Phycol. 2018, 30, 2305-2316. [CrossRef] [PubMed]

33. Adams, J. GreenSeas Resouces. 2017. Available online: https://beaconwales.org/images/GreenSeas_Resources.pdf (accessed on 19 August 2021).

34. Wirtanen, G.; Salo, S. Disinfection in Food Processing-Efficacy Testing of Disinfectants. Rev. Environ. Sci. Bio/Technol. 2003, 2, 293-306. [CrossRef]

35. Berovič, M. Sterilisation in biotechnology. Biotechnol. Annu. Rev. 2005, 11, 257-279. [CrossRef] [PubMed]

36. Doran, P.M. Reactor engineering. In Bioprocess Engineering Principles, 2nd ed.; Doran, P.M., Ed.; Academic Press Ltd: London, UK, 2013; pp. 761-853.

37. Stanton, D. ABEC Breaks Plastic Ceiling again with 6000 L Single-Use Bioreactor. BioProcess International. 2019. Available online: https:/ / bioprocessintl.com/bioprocess-insider/upstream-downstream-processing/abec-breaks-plastic-ceiling-againwith-6000-1-single-use-bioreactor/ (accessed on 17 August 2021).

38. Adams, J.M.M.; Schmidt, A.; Gallagher, J.A. The impact of sample preparation of the macroalgae Laminaria digitata on the production of the biofuels bioethanol and biomethane. J. Appl. Phycol. 2014, 27, 985-991. [CrossRef]

39. Łabowska, M.B.; Michalak, I.; Detyna, J. Methods of extraction, physicochemical properties of alginates and their applications in biomedical field-A review. Open Chem. 2019, 17, 738-762. [CrossRef]

40. Haug, A.; Bjerrum, J.; Buchardt, O.; Olsen, G.E.; Pedersen, C.; Toft, J. The Affinity of Some Divalent Metals for Different Types of Alginates. Acta Chem. Scand. 1961, 15, 1794-1795. [CrossRef]

41. Haug, A.; Smidsrød, O. Strontium-Calcium Selectivity of Alginates. Nat. Cell Biol. 1967, 215, 757. [CrossRef]

42. BSSA. Selection of Stainless Steels for Handling Hydrochloric Acid (HCl). 2021. Available online: https://bssa.org.uk/bssa_ articles /9-selection-of-stainless-steels-for-handling-hydrochloric-acid-hcl/ (accessed on 23 June 2021).

43. BSSA. Selection of Stainless Steels for Handling Sulphuric Acid (H2SO4). 2021. Available online: https://bssa.org.uk/bssa_ articles/selection-of-stainless-steels-for-handling-sulphuric-acid-h2so4/ (accessed on 23 June 2021).

44. European Commision. Commision Regulation 1881/2006 Setting Laximum Levels for Certain Contaminants in Foodstuffs; European Union: Brussels, Belgium, 2006.

45. Raize, O.; Argaman, Y.; Yannai, S. Mechanisms of biosorption of different heavy metals by brown marine macroalgae. Biotechnol. Bioeng. 2004, 87, 451-458. [CrossRef] [PubMed]

46. Marani, D.; Macchi, G.; Pagano, M. Lead precipitation in the presence of sulphate and carbonate: Testing of thermodynamic predictions. Water Res. 1995, 29, 1085-1092. [CrossRef]

47. Nedwed, T.; Clifford, D.A. Feasibility of extracting lead from lead battery recycling site soil using high-concentration chloride solutions. Environ. Prog. 2000, 19, 197-206. [CrossRef] 